\title{
Adverse Effects of Conventional Thrice-Weekly Hemodialysis: Is It Time to Avoid 3-Day Interdialytic Intervals?
}

\author{
Panagiotis I. Georgianos ${ }^{a}$ Pantelis A. Sarafidis ${ }^{b}$ Arjun D. Sinha ${ }^{c}$ Rajiv Agarwalc

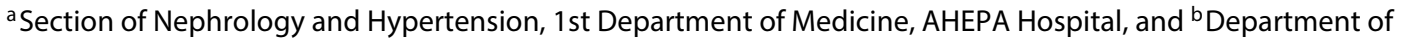 \\ Nephrology, Hippokration Hospital, Aristotle University of Thessaloniki, Thessaloniki, Greece; ' Indiana University School \\ of Medicine and Richard L. Roudebush Veterans Affairs Administration Medical Center, Indianapolis, Ind., USA
}

\section{Key Words}

Long interdialytic interval · Morbidity - Mortality ·

Enhanced-frequency hemodialysis · Extended-time hemodialysis

\begin{abstract}
Background: Maintenance hemodialysis is typically scheduled thrice weekly due to simple logistic reasons; thus, the vast majority of hemodialysis patients receive renal replacement therapy for two shorter 2-day intervals and a longer 3-day interval. As compared to the 2-day interval, we review the ill effects of the longer 3-day interdialytic interval in this report. Summary: Large-scale observational studies show that both cardiovascular-related hospital admissions and mortality occur more frequently on the day following the long interdialytic interval than on any other day of the week. Although the reasons for excess mortality are obscure, several pathophysiologic mechanisms may be involved, such as a greater magnitude of change during the long interdialytic interval in the following parameters: volume status, electrolyte and acid-base status, arterial wall and left ventricle mechanics. These data raise the need for re-examining the issue of timing and frequency of prescribed dialysis regimens in an attempt to improve patient outcomes. Although enhancedfrequency and/or extended-time dialysis schedules may mit-
\end{abstract}

igate the risks of the long interdialytic interval, the benefit of such dialytic modalities on survival is not yet proven. Key Message: This article summarizes currently available epidemiologic and pathophysiologic evidence on the adverse effects related to the long interdialytic interval of thrice-weekly hemodialysis and discusses the need to research further alternative dialysis practices that could mitigate these risks.

(c) 2015 S. Karger AG, Basel

\section{Introduction}

Dialysis treatment is scheduled thrice weekly ever since the inception of hemodialysis as a form of renal replacement therapy for patients with end-stage renal disease (ESRD). Due to reasons not related to health and disease status, but rather to convenience, hemodialysis patients remain without dialysis for a longer interval ( $\sim 3$ days) prior to the first dialysis session of the week. A growing body of observational data supports the hypothesis that morbid and mortal events occur more frequently during the last day of the long interdialytic interval than during any other day of the week [1-3]. If this risk is causally related to the 3 -day interdialytic interval, then there is a need to evaluate timing and frequency of prescribed hemodialysis regimens [4].

\section{KARGER 125}

C 2015 S. Karger AG, Basel

0250-8095/15/0415-0400\$39.50/0
Rajiv Agarwal, MD, FAHA, FASN

Department of Medicine, Indiana University School of Medicine and Richard L. Roudebush Veterans Administration Medical Center 1481 West 10th Street, Indianapolis, IN 46202 (USA)

E-Mail ragarwal@iu.edu 
Table 1. Observational registry studies evaluating the day-of-the-week morbidity and mortality in dialysis patients

\begin{tabular}{|c|c|c|c|c|c|}
\hline Study ID & $\begin{array}{l}\text { Study } \\
\text { design }\end{array}$ & Origin of data & $\begin{array}{l}\text { Observational } \\
\text { period }\end{array}$ & Comparison & $\begin{array}{l}\text { Day-of-week morbidity and } \\
\text { mortality }\end{array}$ \\
\hline $\begin{array}{l}\text { Bleyer et al. } \\
\text { [5] Kidney } \\
\text { Int } 1999\end{array}$ & Retrospective & $\begin{array}{l}375,482 \text { deaths } \\
\text { recorded in the } \\
\text { USRDS registry }\end{array}$ & 1977-1997 & $\begin{array}{l}\text { Difference between the } \\
\text { observed and expected } \\
\text { mortal events on } \\
\text { Monday and Tuesday }\end{array}$ & $\begin{array}{l}\text { Sudden deaths and cardiac } \\
\text { deaths observed on Monday } \\
\text { and Tuesday were higher than } \\
\text { those expected }\end{array}$ \\
\hline $\begin{array}{l}\text { Krishnasamy et al. } \\
\text { [2] Am J Kidney } \\
\text { Dis } 2013\end{array}$ & Retrospective & $\begin{array}{l}14,636 \text { deaths of } \\
\text { dialysis patients } \\
\text { recorded in the } \\
\text { ANZDATA } \\
\text { registry }\end{array}$ & 1999-2008 & $\begin{array}{l}\text { Monday versus the } \\
\text { week average }\end{array}$ & $\begin{array}{l}\text { Higher risk of cardiovascular } \\
\text { death and death related to } \\
\text { hyperkalemia on Monday for } \\
\text { hemodialysis patients receiving } \\
\leq 3 \text { dialysis sessions per week }\end{array}$ \\
\hline
\end{tabular}

We review the evidence associating the long interdialytic interval of thrice-weekly hemodialysis with heightened risk of morbidity and mortality and summarize the pathophysiology of this potentially harmful effect. To mitigate the risk of long interdialytic intervals and the potential benefits of their implementation in clinical practice, we discuss alternative dialysis practices. We conclude with some recommendations for research.

\section{The Long Interdialytic Interval and the Risk for Morbidity and Mortality}

Large registry-based cohort studies [1-3, 5-8] have consistently linked intermittent dialysis schedules with elevated risk of death and cardiovascular-related complications (table 1). In the first study, Bleyer et al. [5] retrospectively evaluated mortality data of the USA dialysis population during 1977-1997 (i.e. patients either on hemodialysis or peritoneal dialysis), enrolled in the United States Renal Data System (USRDS), as well as data from 7,096 patients participating in the USRDS Case Mix Adequacy Study (CMAS). The investigators observed that among hemodialysis patients, Mondays were associated with increased risk of sudden and cardiac death $(18.4 \%$ of sudden deaths and $18.1 \%$ of cardiac deaths occurred on Mondays relative to $14.3 \%$ expected, $\mathrm{p}<0.00001$ ) [5]. The next most common day of occurrence of sudden and cardiac deaths was Tuesday (15.4\% relative to $14.3 \%$ expected, $\mathrm{p}<0.00001)$. In contrast, deaths from non-cardiac causes in hemodialysis patients and deaths from both cardiac and non-cardiac causes in patients receiving peritoneal dialysis were evenly distributed throughout the week. When analysis was restricted to the CMAS participants, for whom data on dialysis schedules were available, it was shown that for patients being on a Monday-WednesdayFriday schedule, compared to $14.3 \%$ expected deaths, deaths were more on Mondays: sudden deaths were $20.8 \%$ and cardiac deaths $20.2 \%$ [5]. A similar trend was found on Tuesdays for patients being on a Tuesday-ThursdaySaturday (TTS) schedule.

Three subsequent cohort studies evaluating morbidity and mortality data from various populations provide additional support to the potential link of 3-day interval with heightened cardiovascular risk [1-3]. A retrospective analysis of 32,065 hemodialysis patients participating 
in the End-Stage Renal Disease Clinical Performance Measures Project in the USA during 2004-2007 [1] showed that, compared to any other day of the week, the first dialysis day of the week was associated with higher risk of all-cause mortality (22.1 vs. 18.0 deaths per 100 person-years of follow-up, $\mathrm{p}<0.001)$ and cardiovascular mortality (10.2 vs. $7.5, \mathrm{p}<0.001)$ [1]. A similar day-ofweek pattern was evident for cardiovascular-related hospital admissions (rates per 100 person-years: 44.2 vs. 19.7, $\mathrm{p}<0.001)$.

A post hoc analysis of data from 22,163 hemodialysis patients participating in Dialysis Outcomes and Patterns Practice Study (DOPPS) [3] allowed comparisons from around the world. In the USA, Mondays were associated with $41 \%$ higher risk of death relative to the 7 -day average $(\mathrm{p}<0.001)$; in Europe, the death risk was $34 \%$ higher $(\mathrm{p}=$ 0.001 ). In contrast, for Japanese patients, a $27 \%$ higher risk of death was noted on Mondays, but this did not reach statistical significance compared to the 7-day average $(p=0.154)$ [3]. A similar trend for the day-of-week mortality was also evident in patients who were on a TTS dialysis schedule, as Tuesdays were associated with a significant 39, 22 and $41 \%$ higher risk of all-cause mortality relative to the 7-day average in the USA, European and Japanese patients, respectively. In comparison to the noncardiovascular deaths, the association between day-ofweek mortality and dialysis schedule was stronger in the case of cardiovascular mortality.

Using the Australian and New Zealand Dialysis and Transplant (ANZDATA) Registry, the day-of-week and mortality relationship was explored in 14,636 ESRD patients who died between 1999 and 2008 [2]. This study showed that cardiac deaths were more likely to occur on Mondays than on any other day of the week in hemodialysis patients receiving $\leq 3$ dialysis treatments per week (odds ratio (OR) 1.26, 95\% confidence intervals (CI) $1.14-1.40, \mathrm{p}<0.001)$. Similarly, Mondays were also associated with $89 \%$ higher risk of death related to hyperkalemia (OR 1.89, $\mathrm{p}=0.008)$ and $17 \%$ higher risk of sudden cardiac death (OR 1.17, $\mathrm{p}=0.004)$ compared to any other day of the week. The next most common day of mortality occurrence was Tuesday (OR 1.08, 95\% CI 0.97-1.20, p = $0.10)$. In contrast, mortal events were evenly distributed across the week in patients receiving $>3$ dialysis treatments per week, in patients receiving home hemodialysis and in patients receiving peritoneal dialysis [2].

Many of the above studies were limited by the fact that the exact timing of events was not available. This did not allow study investigators to examine whether deaths and cardiovascular complications had occurred before, dur- ing or after the first weekly dialysis session. A retrospective analysis of 80 cases of sudden cardiac death during 1995-2003 in 5 dialysis units in the USA addressed this issue; the last 12 -hour period of the 3 -day interval (i.e. the period of the highest accumulation of metabolic and volume-related parameters) was associated with a 3-fold elevated risk of sudden death [6].

A limitation of all the above studies is that no causeand-effect association between day-of-week mortality and dialysis scheduling is possible, given their retrospective and observational design.

\section{Pathophysiologic Background of the Adverse Outcomes Related to the Long Interdialytic}

The above findings are in line with the 'Peak Concentration Hypothesis', which was introduced by Keshaviah et al. [9] in 1989. This hypothesis suggested that the peaks in concentrations of urea may raise the risk of overt uremic toxicity in patients receiving intermittent thriceweekly hemodialysis, despite the fact that both hemodialysis and peritoneal dialysis patients may have similar time-averaged urea concentration for the same dialysis adequacy [9]. Despite absence of direct evidence that urea per se is toxic [10], the principles of this theory may be relevant to shifts in metabolic and volume-related parameters between dialysis treatments, generating hypotheses for the mechanistic background of increased risk of morbidity and mortality associated with the long interdialytic interval. The most important of these mechanisms are depicted in figure 1 and are summarized below.

\section{Interdialytic Weight Gain and Blood Pressure}

Among hemodialysis patients, elevated blood pressure (BP), particularly when recorded outside of the dialysis unit either with home or with ambulatory BP monitoring, is a strong cardiovascular risk factor $[11,12]$. Unlike the general hypertensive population with normal renal function or people with early stage chronic kidney disease, patients on maintenance hemodialysis display markedly impaired patterns and rhythms of BP during the interdialytic interval. Among hemodialysis patients, BP steadily increases during the interdialytic interval and the rate of BP increment is directly proportional to the interdialytic weight gain $[13,14]$. Notably, the impact of interdialytic weight gain is superimposed on the circadian variation of BP. In a study investigating the chronobiology of $\mathrm{BP}$ rhythms over the 3-day interdialytic interval with the use of home BP monitoring, it was shown that interdia- 


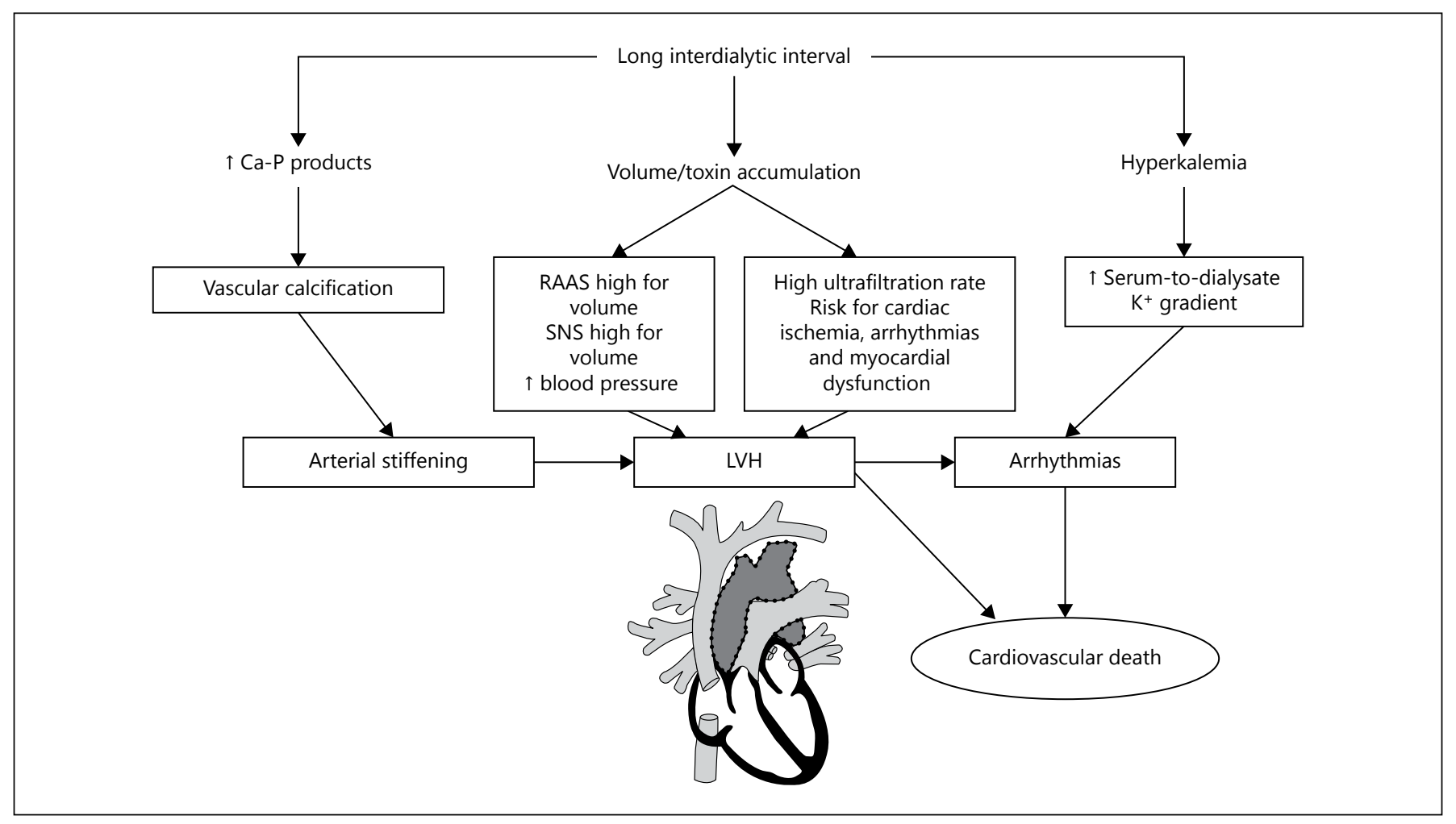

Fig. 1. Putative pathophysiological mechanisms of the harmful effects of the long interdialytic interval.

lytic increase in systolic and diastolic BP was not linear and that it reached a plateau after the first $48 \mathrm{~h}$ elapsed from dialysis [15]. In addition, the increment in systolic $\mathrm{BP}$ was greater than that in the diastolic BP, resulting in progressive amplification of pulse pressure during the interdialytic interval. This time-dependent amplification of pulse pressure suggests that patients receiving conventional thrice-weekly hemodialysis may accumulate a potent additional cardiovascular risk factor during the interdialytic interval that would be most pronounced during the third day after dialysis [15].

In addition to elevated interdialytic BP, excess volume accumulation over the long interdialytic interval also influences hemodynamic stability during dialysis [16]. This is due to the need for more aggressive ultrafiltration during the first dialysis session of the week, resulting in greater shifts of volume and pressure within dialysis. Apart from raising the risk of symptomatic intradialytic hypotension, associated with excess mortality [17], aggressive ultrafiltration is proposed to promote sub-clinical cardiac stunning and cardiomyocyte ischemia, factors that may also worsen left ventricular function [18].

Long Interdialytic Interval and Mortality Risk

\section{Shifts in Electrolytes and Acid-Base Balance}

Potassium

Both hyper and hypokalemia are well-known risk factors of cardiac arrhythmias and sudden death [19]. Fluxes in potassium levels during the intra and interdialytic periods represent another important mechanism that could explain the day-of-week pattern of mortality. In the study by Bleyer et al. [6], patients who died during the last 12-hour period of the long interdialytic interval had higher average serum potassium levels than that of the survivors. Genovesi et al. [7] showed that hemodialysis patients with pre-dialysis serum potassium levels $>6.0$ $\mathrm{mmol} / \mathrm{l}$ had a 2.7 -fold elevated risk of sudden cardiac death during the 3-year follow-up. In addition, Krishnasamy et al. [2] showed that among patients receiving $\leq 3$ dialysis treatments per week, deaths related to hyperkalemia occurred more frequently on Mondays than on any other day of the week. In addition, high potassium fluxes during the first weekly dialysis session may also be of major clinical significance. Karnik et al. [8] reported that use of low potassium concentrations (i.e. $0-1 \mathrm{mEq} / \mathrm{l}$ ) in the dialysate was associated with increased risk of sudden cardiac death. In a subsequent study, Pun et al. [20] 
confirmed that performing dialysis with a low potassium bath against elevated serum potassium leads to high imbalances of the potassium gradient between the intracellular and extracellular body compartments, raising the risk of serious arrhythmias and sudden death. However, all the studies mentioned above were observational; cause-and-effect relationship cannot be established.

\section{Acid-Base Imbalances}

Hemodialysis patients have significantly lower serum bicarbonate levels and lower $\mathrm{pH}$ after the long interdialytic period [21]. The relationship of pre-dialysis serum bicarbonate levels to subsequent mortality is U-shaped [22]. Whether worsened acid-base balance exerts an effect on the excess mortality during the 3-day interdialytic interval remains unknown.

\section{Calcium and Phosphate}

Ionized calcium regulates myocardial contractility and vascular tone [23]. Serum concentrations of calcium and phosphate were significantly higher after the long interdialytic interval relative to the regular 2-day interdialytic interval [24]. In the long term, elevated calcium phosphate product is involved in the pathogenesis of vascular calcification, which impairs arterial wall structure [25, 26]. Since impaired mineral metabolism is a strong and independent predictor of mortality in hemodialysis [27], the intermittently higher calcium phosphate product during the long interdialytic interval may worsen the outcomes in these patients. Furthermore, recent studies have shown that high dialysate calcium concentrations acutely raise $\mathrm{BP}$ and worsen arterial compliance during dialysis [28]. Prospective studies support that session-to-session variability in serum calcium and phosphate levels is a predictor of mortality in hemodialysis [29, 30]. Thus, shifts in calcium phosphate product may be also implicated in elevated risk of mortality associated with the long interdialytic interval.

\section{Arterial Stiffness and Wave Reflections}

Hemodialysis acutely reduces the augmentation component of central systolic pressures, resulting probably from decrease in the amount of the pulse wave reflected at peripheral sites, but has no effect on arterial compliance [31]. Furthermore, indices of wave reflections are increased during 3 -day interdialytic period $(30 \%$ more than during a regular 2-day interdialytic interval), and these changes are directly related to the interdialytic weight gain [32]. The increase in peak and end systolic pressures in the ascending aorta raises myocardial pres- sure afterload and myocardial oxygen demand; reduced sub-endocardial blood flow during diastole favors the occurrence of acute ischemic cardiac events [33]. In the long term, this intermittent effect would further promote left ventricular hypertrophy $(\mathrm{LVH})$, raising the risk of cardiac arrhythmias and sudden death.

\section{Left Ventricular Hypertrophy}

The development and progression of LVH represents a strong predictor of cardiovascular mortality in hemodialysis [34]. A higher left ventricular pre-load and the consequent higher mechanical stretch of myocardial fibers during the period of the greatest fluid accumulation (i.e. the last 12-hour period of the long interdialytic interval) could be a precipitating factor for acute pulmonary edema and sudden cardiac death. This is supported by the results from the aforementioned study by Foley et al. [1] in which hospital admissions for congestive heart failure and cardiac arrhythmias were shown to occur more frequently on the days following the long interdialytic interval. Cardiac arrhythmias among hemodialysis patients may be provoked by capillary rarefaction and cardiomyocyte ischemia, which are typical features of uremic cardiomyopathy [35].

\section{Hormonal Status and Sympathetic Overactivity}

In the general population, Mondays are associated with higher risk of acute myocardial infraction and sudden cardiac death than any other day of the week $[36,37]$. This day-of-week pattern has been attributed to changes in physiologic circadian patterns of various parameters, including the temporal plasma catecholamine release and the peaks and falls in plasma cortisol levels [36-38]. Another contributing factor is proposed to be the overactivity of the sympathetic nervous system. Hemodialysis patients maybe particularly susceptible to the adverse cardiovascular effects of circadian and temporal changes in hormonal status and the activity of sympathetic nervous system, as majority of these patients have documented cardiovascular disease and impaired compensatory vascular mechanisms [39].

\section{Dialysis Practices and Patterns Aiming at Shorter Interdialytic Intervals}

\section{Enhanced-Frequency Hemodialysis}

The impact of 6 times per week in-center hemodialysis versus conventional thrice-weekly hemodialysis was examined by the 12-month Frequent Hemodialysis Net- 
work (FHN) randomized trial [40]. This study showed that enhanced-frequency hemodialysis was associated with $39 \%$ reduction in the risk of death or change in left ventricular mass index (LVMI), as assessed by MRI (hazard ratio (HR) $0.61,95 \%$ CI $0.46-0.82$ ), and with $30 \%$ reduced risk of death or change in the physical health composite score of the RAND 36-item health survey (HR $0.70,95 \%$ CI $0.53-0.92$ ) [40]. The major finding of the FHN trial was the improvement in LVH with short sessions of daily hemodialysis; notably, LVH regression has been clearly associated with reduced mortality in hemodialysis patients [34]. Other benefits of enhanced-frequency dialysis regimens include improvement in phosphorus homeostasis, BP control, arterial stiffness, total body water and self-reported quality of life [41-45].

Effects of enhanced-frequency hemodialysis on 'hard' outcomes or mortality were evaluated in recent retrospective cohort studies. The following 2 studies showed an improvement in mortality. In a retrospective cohort study including 1,873 patients who were receiving daily home hemodialysis and 9,365 matched controls receiving thrice-weekly hemodialysis selected from the USRDS database during 2005-2008, Weinhandl et al. [46] showed that daily home hemodialysis was associated with $13 \%$ lower risk of all-cause mortality than that of in-center thrice-weekly hemodialysis (HR 0.87, 95\% CI 0.78-0.97). Another retrospective study, enrolling 338 patients from the International Quotidian Dialysis Registry who received intensive home hemodialysis between January 2000 and August 2010 and another 1,388 matched controls participating in the DOPPS study who received thrice-weekly hemodialysis during the same time-period, showed that intensive home hemodialysis is associated with $45 \%$ reduction in the risk of all-cause mortality (HR 0.55, 95\% CI 0.34-0.87) [47].

In contrast to the above, survival benefits of enhancedfrequency hemodialysis were not confirmed in the study by Suri et al. [48], which showed that during 1,382 patient-years of follow-up, 318 patients receiving short sessions of daily hemodialysis ( $>5$ times per week) had $60 \%$ higher risk of death than 575 matched controls receiving thrice-weekly hemodialysis (HR 1.60, 95\% CI 1.1-2.3). This excess mortality may be due to incomparability of groups at study initiation with respect to several parameters, such as comorbidities, type of dialysis access, BP control and residual diuresis.

These modalities were also related to harms, including elevated risks of vascular access complications, worsened residual renal function and increased burden of therapy,

Long Interdialytic Interval and

Mortality Risk resulting in higher rates of method discontinuation among patients scheduled for enhanced-frequency dialysis $[4,49,50]$. Vascular access events emerge as the most important issue; although plausible, the currently available evidence is inconclusive, as in only one of the two randomized studies in the field frequency of vascular access interventions was more common in patients receiving frequent dialysis [50]. Deterioration of residual renal function was noted only in post hoc analyses of the main FHN trial [49], but also in the primary results [40], while burden of therapy and method discontinuation rates should be considered 'softer' end points influenced by several confounding parameters. Although these complications cannot be neglected, they should not overshadow the currently available evidence, which is at least suggestive of a beneficial impact of enhanced-frequency hemodialysis on intermediate cardiovascular end points and mortality.

\section{Extended-Time Nocturnal Hemodialysis}

Another treatment option toward attenuation of the mortality risk attributed to conventional thrice-weekly dialysis regimens could be extended-time, home or incenter nocturnal hemodialysis, which although not more frequent, reduces the duration of the long interdialytic period. Ok et al. [51] prospectively followed 247 patients assigned to 8-hour in-center nocturnal hemodialysis and 247 matched controls assigned to conventional thriceweekly hemodialysis for 12 months. Extended-time nocturnal hemodialysis was associated with $72 \%$ reduced risk of all-cause mortality relative to conventional hemodialysis. A subsequent prospective cohort study compared risk of all-cause mortality during a mean follow-up of 24 months in 746 patients who initiated extended-time, incenter, nocturnal hemodialysis in 77 dialysis centers of a large dialysis-care provider in the USA during 2006-2007 and in 2,062 controls who remained on conventional thrice-weekly hemodialysis [52]. Nocturnal hemodialysis was associated with $25 \%$ reduction in the risk of all-cause mortality (HR 0.75, 95\% CI 0.61-0.91); furthermore, no day-of-week effect was observed on occurrence of mortal events during the follow-up [52]. However, once again, these observations have to be confirmed in future randomized clinical trials; cause-and-effect relationships cannot be assured.

\section{Alternate-Day Hemodialysis}

In a pilot study, 9 prevalent hemodialysis patients were switched to alternate-day hemodialysis for 12 months and another 9 patients remained on convention- 
al thrice-weekly hemodialysis [53] Improvements in LVMI, in BP control and in several other biochemical factors were observed, but these results are only preliminary.

\section{Research Implications and Practical Considerations}

The benefit of enhanced-frequency and/or extendedtime dialysis regimens on hard outcomes and cost effectiveness of these modalities remain unclear. Until such data become available, physicians may need to develop clinically feasible dialysis practices in order to attenuate the risk of long interdialytic intervals for patients who receive standard thrice-weekly hemodialysis. Interventions could include some of the following. First, reduction of the long interdialytic period, with prescription of an additional dialysis treatment on Saturdays or Mondays in patients carrying a high risk of adverse cardiovascular events during the long interdialytic interval (i.e. patients with severe heart failure, high interdialytic weight gain and frequent episodes of intradialytic hypotension) [54]. In addition, treatment interventions during the first dialysis session of the week, after the long interdialytic interval, may also be of benefit. Such interventions include extending the duration of this session in order to reduce the rate of volume withdrawal and individualized prescription of dialysate potassium to avoid high potassium shifts [54]. Last, interventions that target reduction of the risk of hyperkalemia during the long interdialytic interval, such as dietary consultation of non-adherent patients and administration of drugs, to reduce absorption of dietary potassium may improve potassium homeostasis during the long interdialytic period $[54,55]$. Diets avoiding animal protein in preference for plant protein may mitigate acidosis; such approaches are testable in pilot clinical trials.

All the above therapeutic approaches may not be relevant for some specific sub-populations of ESRD patients, that is, patients who initiate renal replacement therapy or prevalent dialysis patients with preserved residual renal function. High residual renal function offers several advantages to dialysis patients, including higher fluid and sodium removal, more effective potassium excretion, higher middle-molecule clearance and reduced LVH [56]. On the basis of a relatively higher capacity to maintain homeostasis of volume and metabolic parameters over a longer out-of-dialysis period, twice-weekly hemodialysis is suggested to be a sufficient dialysis dose for such patients [57]. This notion is supported by recent observational studies that show that twice-weekly hemodialysis is associated with a slower reduction of residual renal function, fewer episodes of intradialytic hypotension, improved health-related quality of life and higher survival rates as compared with conventional thriceweekly hemodialysis [58-60]. However, these potential benefits need to be tested in properly designed randomized trials.

\section{Conclusion}

Although a cause-and-effect relationship between day-of-week mortality and dialysis scheduling remains unproven, if a cause-and-effect relationship exists, it may be due to magnified fluctuations in volume status and BP, electrolyte imbalances and changes in arterial wall parameters during the long interdialytic interval. Clinical studies evaluating potential harms and benefits of practices with altered timing and frequency of prescribed hemodialysis therapy have provided promising results on intermediate outcomes. Additional randomized clinical trials evaluating hard end points are urgently warranted to elucidate the impact of these alternative dialytic modalities on survival. In the meantime, individualized prescription of the dialysis frequency and duration along with close monitoring of our patients appear to be the most appropriate therapeutic approaches to lessen the risk of adverse events during the long interdialytic interval and improve the way we deliver dialysis.

\section{Disclosure Statement}

Authors have no conflicts of interest to disclose.

\section{References}

Am J Nephrol 2015;41:400-408 DOI: $10.1159 / 000435842$
1 Foley RN, Gilbertson DT, Murray T, Collins AJ: Long interdialytic interval and mortality among patients receiving hemodialysis. $\mathrm{N}$ Engl J Med 2011;365:1099-1107.

2 Krishnasamy R, Badve SV, Hawley CM, McDonald SP, Boudville N, Brown FG, Polkinghorne $\mathrm{KR}$, Bannister $\mathrm{KM}$, Wiggins $\mathrm{KJ}$, Clayton P, Johnson DW: Daily variation in death in patients treated by long-term dialysis: comparison of in-center hemodialysis to peritoneal and home hemodialysis. Am J Kidney Dis 2013;61:96-103.

3 Zhang H, Schaubel DE, Kalbfleisch JD, BraggGresham JL, Robinson BM, Pisoni RL, Canaud B, Jadoul M, Akiba T, Saito A, Port FK, Saran R: Dialysis outcomes and analysis of practice patterns suggests the dialysis schedule affects day-of-week mortality. Kidney Int 2012;81:1108-1115. 
4 Diaz-Buxo JA, White SA, Himmele R: Frequent hemodialysis: a critical review. Semin Dial 2013;26:578-589.

5 Bleyer AJ, Russell GB, Satko SG: Sudden and cardiac death rates in hemodialysis patients. Kidney Int 1999;55:1553-1559.

6 Bleyer AJ, Hartman J, Brannon PC, ReevesDaniel A, Satko SG, Russell G: Characteristics of sudden death in hemodialysis patients. Kidney Int 2006;69:2268-2273.

7 Genovesi S, Valsecchi MG, Rossi E, Pogliani D, Acquistapace I, De Cristofaro V, Stella A, Vincenti A: Sudden death and associated factors in a historical cohort of chronic haemodialysis patients. Nephrol Dial Transplant 2009;24:2529-2536.

8 Karnik JA, Young BS, Lew NL, Herget M, Dubinsky C, Lazarus JM, Chertow GM: Cardiac arrest and sudden death in dialysis units. Kidney Int 2001;60:350-357.

9 Keshaviah PR, Nolph KD, Van Stone JC: The peak concentration hypothesis: a urea kinetic approach to comparing the adequacy of continuous ambulatory peritoneal dialysis (CAPD) and hemodialysis. Perit Dial Int 1989; 9:257-260.

10 Sherman RA: The peak concentration hypothesis - a justification for inadequate therapy? Semin Dial 1994;7:318-320.

11 Agarwal R: Blood pressure and mortality among hemodialysis patients. Hypertension 2010;55:762-768.

12 Agarwal R, Flynn J, Pogue V, Rahman M, Reisin E, Weir MR: Assessment and management of hypertension in patients on dialysis. J Am Soc Nephrol 2014;25:1630-1646.

13 Agarwal R, Light RP: Arterial stiffness and interdialytic weight gain influence ambulatory blood pressure patterns in hemodialysis patients. Am J Physiol Renal Physiol 2008; 294:F303-F308.

14 Kelley K, Light RP, Agarwal R: Trended cosinor change model for analyzing hemodynamic rhythm patterns in hemodialysis patients. Hypertension 2007;50:143-150.

15 Agarwal R, Light RP: Chronobiology of arterial hypertension in hemodialysis patients: implications for home blood pressure monitoring. Am J Kidney Dis 2009;54:693-701.

16 Agarwal R: How can we prevent intradialytic hypotension? Curr Opin Nephrol Hypertens 2012;21:593-599.

17 Shoji T, Tsubakihara Y, Fujii M, Imai E: Hemodialysis-associated hypotension as an independent risk factor for two-year mortality in hemodialysis patients. Kidney Int 2004;66: 1212-1220.

18 Zuidema MY, Dellsperger KC: Myocardial stunning with hemodialysis: clinical challenges of the cardiorenal patient. Cardiorenal Med 2012;2:125-133.

19 Pun PH, Herzog CA, Middleton JP: Improving ascertainment of sudden cardiac death in patients with end stage renal disease. Clin J Am Soc Nephrol 2012;7:116-122.

20 Pun PH, Lehrich RW, Honeycutt EF, Herzog CA, Middleton JP: Modifiable risk factors as- sociated with sudden cardiac arrest within hemodialysis clinics. Kidney Int 2011;79:218227.

21 John Gennari F: Very low and high predialysis serum bicarbonate levels are risk factors for mortality: what are the appropriate interventions? Semin Dial 2010;23:253-257.

$22 \mathrm{Wu}$ DY, Shinaberger CS, Regidor DL, McAllister CJ, Kopple JD, Kalantar-Zadeh K: Association between serum bicarbonate and death in hemodialysis patients: is it better to be acidotic or alkalotic? Clin J Am Soc Nephrol 2006;1:70-78.

23 Fellner SK, Lang RM, Neumann A, Spencer KT, Bushinsky DA, Borow KM: Physiological mechanisms for calcium-induced changes in systemic arterial pressure in stable dialysis patients. Hypertension 1989;13:213-218.

24 Sigrist MK, Devlin L, Taal MW, Fluck RJ, McIntyre CW: Length of interdialytic interval influences serum calcium and phosphorus concentrations. Nephrol Dial Transplant 2005;20:1643-1646.

25 Asci G, Ok E, Savas R, Ozkahya M, Duman S, Toz H, Kayikcioglu M, Branscum AJ, MonierFaugere MC, Herberth J, Malluche HH: The link between bone and coronary calcifications in CKD-5 patients on haemodialysis. Nephrol Dial Transplant 2011;26:1010-1015.

26 Briet M, Boutouyrie P, Laurent S, London GM: Arterial stiffness and pulse pressure in CKD and ESRD. Kidney Int 2012;82:388400.

27 Fukagawa M, Kido R, Komaba H, Onishi Y, Yamaguchi T, Hasegawa T, Kurita N, Fukuma S, Akizawa T, Fukuhara S: Abnormal mineral metabolism and mortality in hemodialysis patients with secondary hyperparathyroidism: evidence from marginal structural models used to adjust for time-dependent confounding. Am J Kidney Dis 2014;63:979-987.

28 LeBeouf A, Mac-Way F, Utescu MS, Chbinou N, Douville P, Desmeules S, Agharazii M: Effects of acute variation of dialysate calcium concentrations on arterial stiffness and aortic pressure waveform. Nephrol Dial Transplant 2009;24:3788-3794.

29 Levitt H, Smith KG, Rosner MH: Variability in calcium, phosphorus, and parathyroid hormone in patients on hemodialysis. Hemodial Int 2009;13:518-525.

30 Tentori F, Blayney MJ, Albert JM, Gillespie BW, Kerr PG, Bommer J, Young EW, Akizawa T, Akiba T, Pisoni RL, Robinson BM, Port FK: Mortality risk for dialysis patients with different levels of serum calcium, phosphorus, and PTH: the Dialysis Outcomes and Practice Patterns Study (DOPPS). Am J Kidney Dis 2008;52:519-530.

31 Georgianos PI, Sarafidis PA, Malindretos P, Nikolaidis P, Lasaridis AN: Hemodialysis reduces augmentation index but not aortic or brachial pulse wave velocity in dialysis-requiring patients. Am J Nephrol 2011;34:407-414.

32 Georgianos PI, Sarafidis PA, Haidich AB, Karpetas A, Stamatiadis D, Nikolaidis P, Lasaridis AN: Diverse effects of interdialytic in- tervals on central wave augmentation in haemodialysis patients. Nephrol Dial Transplant 2013;28:2160-2169.

33 Protogerou AD, Papaioannou TG, Blacher J, Papamichael CM, Lekakis JP, Safar ME: Central blood pressures: do we need them in the management of cardiovascular disease? Is it a feasible therapeutic target? J Hypertens 2007; 25:265-272.

34 Zoccali C, Benedetto FA, Mallamaci F, Tripepi G, Giacone G, Stancanelli B, Cataliotti A, Malatino LS: Left ventricular mass monitoring in the follow-up of dialysis patients: prognostic value of left ventricular hypertrophy progression. Kidney Int 2004;65:1492-1498.

35 Glassock RJ, Pecoits-Filho R, Barberato SH: Left ventricular mass in chronic kidney disease and ESRD. Clin J Am Soc Nephrol 2009; 4(suppl 1):S79-S91.

36 Gnecchi-Ruscone T, Piccaluga E, Guzzetti S, Contini M, Montano N, Nicolis E: Morning and Monday: critical periods for the onset of acute myocardial infarction. The GISSI 2 Study experience. Eur Heart J 1994;15:882-887.

37 Muller JE, Stone PH, Turi ZG, Rutherford JD, Czeisler CA, Parker C, Poole WK, Passamani E, Roberts R, Robertson T, et al: Circadian variation in the frequency of onset of acute myocardial infarction. N Engl J Med 1985; 313:1315-1322.

38 Turton MB, Deegan T: Circadian variations of plasma catecholamine, cortisol and immunoreactive insulin concentrations in supine subjects. Clin Chim Acta 1974;55:389-397.

39 Kahn MR, Robbins MJ, Kim MC, Fuster V: Management of cardiovascular disease in patients with kidney disease. Nat Rev Cardiol 2013;10:261-273.

40 Chertow GM, Levin NW, Beck GJ, Depner TA, Eggers PW, Gassman JJ, Gorodetskaya I, Greene T, James S, Larive B, Lindsay RM, Mehta RL, Miller B, Ornt DB, Rajagopalan S, Rastogi A, Rocco MV, Schiller B, Sergeyeva O, Schulman G, Ting GO, Unruh ML, Star RA, Kliger AS: In-center hemodialysis six times per week versus three times per week. N Engl J Med 2010;363:2287-2300.

41 Chan CT, Greene T, Chertow GM, Kliger AS, Stokes JB, Beck GJ, Daugirdas JT, Kotanko P, Larive B, Levin NW, Mehta RL, Rocco M, Sanz J, Yang PC, Rajagopalan S: Effects of frequent hemodialysis on ventricular volumes and left ventricular remodeling. Clin J Am Soc Nephrol 2013;8:2106-2116.

42 Demirci MS, Celik G, Ozkahya M, Tumuklu M, Toz H, Asci G, Duman S, Basci A, Kircelli F, Ozdogan O, Demirci C, Can L, Isik IO, Ok E: Effects of thrice weekly nocturnal hemodialysis on arterial stiffness. Atherosclerosis 2012;220:477-485.

43 Hall YN, Larive B, Painter P, Kaysen GA, Lindsay RM, Nissenson AR, Unruh ML, Rocco MV, Chertow GM: Effects of six versus three times per week hemodialysis on physical performance, health, and functioning: frequent hemodialysis network (FHN) randomized trials. Clin J Am Soc Nephrol 2012;7:782-794. 
44 Kaysen GA, Greene T, Larive B, Mehta RL, Lindsay RM, Depner TA, Hall YN, Daugirdas JT, Chertow GM: The effect of frequent hemodialysis on nutrition and body composition: frequent Hemodialysis Network Trial. Kidney Int 2012;82:90-99.

45 Ornt DB, Larive B, Rastogi A, Rashid M, Daugirdas JT, Hernandez A, Kurella Tamura M, Suri RS, Levin NW, Kliger AS: Impact of frequent hemodialysis on anemia management: results from the Frequent Hemodialysis Network (FHN) Trials. Nephrol Dial Transplant 2013;28:1888-1898.

46 Weinhandl ED, Liu J, Gilbertson DT, Arneson TJ, Collins AJ: Survival in daily home hemodialysis and matched thrice-weekly in-center hemodialysis patients. J Am Soc Nephrol 2012;23:895-904.

47 Nesrallah GE, Lindsay RM, Cuerden MS, Garg AX, Port F, Austin PC, Moist LM, Pierratos $\mathrm{A}$, Chan $\mathrm{CT}$, Zimmerman D, Lockridge RS, Couchoud C, Chazot C, Ofsthun N, Levin A, Copland M, Courtney M, Steele A, McFarlane PA, Geary DF, Pauly RP, Komenda P, Suri RS: Intensive hemodialysis associates with improved survival compared with conventional hemodialysis. J Am Soc Nephrol 2012;23:696-705.

48 Suri RS, Lindsay RM, Bieber BA, Pisoni RL, Garg AX, Austin PC, Moist LM, Robinson BM, Gillespie BW, Couchoud CG, Galland R, Lacson EK Jr, Zimmerman DL, Li Y, Nesrallah GE: A multinational cohort study of in- center daily hemodialysis and patient survival. Kidney Int 2013;83:300-307.

49 Daugirdas JT, Greene T, Rocco MV, Kaysen GA, Depner TA, Levin NW, Chertow GM, Ornt DB, Raimann JG, Larive B, Kliger AS: Effect of frequent hemodialysis on residual kidney function. Kidney Int 2013;83:949-958.

50 Suri RS, Larive B, Sherer S, Eggers P, Gassman J, James SH, Lindsay RM, Lockridge RS, Ornt DB, Rocco MV, Ting GO, Kliger AS: Risk of vascular access complications with frequent hemodialysis. J Am Soc Nephrol 2013;24: 498-505.

51 Ok E, Duman S, Asci G, Tumuklu M, Onen Sertoz O, Kayikcioglu M, Toz H, Adam SM, Yilmaz M, Tonbul HZ, Ozkahya M: Comparison of 4- and 8-h dialysis sessions in thriceweekly in-centre haemodialysis: a prospective, case-controlled study. Nephrol Dial Transplant 2011;26:1287-1296.

52 Lacson E Jr, Xu J, Suri RS, Nesrallah G, Lindsay R, Garg AX, Lester K, Ofsthun N, Lazarus M, Hakim RM: Survival with three-times weekly in-center nocturnal versus conventional hemodialysis. J Am Soc Nephrol 2012; 23:687-695.

53 Katopodis KP, Dounousi E, Challa A, Pappas K, Kalaitzidis R, Siamopoulos KC: Switch from conventional to every other day hemodialysis: a comparison pilot study. ASAIO J 2009;55:41-46.

54 Flythe JE, Lacson E Jr: Outcomes after the long interdialytic break: implications for the dialytic prescription. Semin Dial 2012;25: $1-8$.

55 Mathialahan T, Sandle GI: Dietary potassium and laxatives as regulators of colonic potassium secretion in end-stage renal disease. Nephrol Dial Transplant 2003;18:341-347.

56 Vilar E, Farrington K: Emerging importance of residual renal function in end-stage renal failure. Semin Dial 2011;24:487-494.

57 Kalantar-Zadeh K, Unruh M, Zager PG, Kovesdy CP, Bargman JM, Chen J, Sankarasubbaiyan S, Shah G, Golper T, Sherman RA, Goldfarb DS: Twice-weekly and incremental hemodialysis treatment for initiation of kidney replacement therapy. Am J Kidney Dis 2014;64:181-186.

58 Bieber B, Qian J, Anand S, Yan Y, Chen N, Wang M, Wang M, Zuo L, Hou FF, Pisoni RL, Robinson BM, Ramirez SP: Two-times weekly hemodialysis in China: frequency, associated patient and treatment characteristics and Quality of Life in the China Dialysis Outcomes and Practice Patterns study. Nephrol Dial Transplant 2014;29:1770-1777.

59 Hanson JA, Hulbert-Shearon TE, Ojo AO, Port FK, Wolfe RA, Agodoa LY, Daugirdas JT: Prescription of twice-weekly hemodialysis in the USA. Am J Nephrol 1999;19:625-633.

60 Zhang M, Wang M, Li H, Yu P, Yuan L, Hao C, Chen J, Kalantar-Zadeh K: Association of initial twice-weekly hemodialysis treatment with preservation of residual kidney function in ESRD patients. Am J Nephrol 2014;40:140-150. 